Laporan Penelitian

\title{
KRITERIA PERFORMANSI ELEMEN WAYFINDING PADA BANGUNAN PERBELANJAAN
}

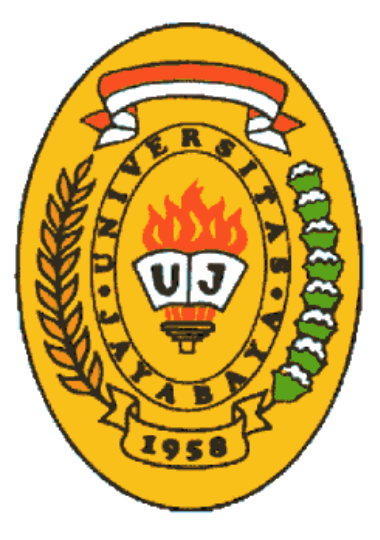

Penyusun :

Adityarini Natalisa, S.T., M.T.

PROGRAM STUDI ARSITEKTUR

FAKULTAS TEKNIK SIPIL DAN PERENCANAAN

UNIVERSITAS JAYABAYA

2014 


\title{
KRITERIA PERFORMANSI ELEMEN WAYFINDING \\ PADA BANGUNAN PERBELANJAAN
}

\author{
Adityarini Natalisa ${ }^{1}$
}

Memasuki era tahun 1990 hingga sekarang fenomena pembangunan gedung Pusat Perbelanjaan, khususnya kota-kota di Indonesia berkembang dengan pesat. Keberhasilan ekonomi suatu kota sering ditandai dengan pertumbuhan pusat perbelanjaan modern, yang secara komersial disebut dengan 'mall', 'plaza', 'junction', atau bahkan 'city'. Yang menjadi permasalahan berikutnya berkaitan dengan pengguna itu sendiri, baik dari kuantitas maupun keragaman karakteritik pengunjungnya. Yang paling sering ditemui adalah anak-anak yang hilang dan tersesat, kesulitan mencari tempat yang dituju, kehilangan orientasi dalam gedung, maupun ketidakjelasan arah atau tanda sirkulasi. Hal-hal tersebut dalam ilmu Arsitektur dikenal dengan permasalahan wayfinding.

Weisman (1981) menyatakan bahwa fitur spasial visual lingkungan, seperti kesederhanaan, bentuk yang baik, akses visual, tanda-tanda dan fitur arsitektur yang tepat adalah elemen kunci yang paling penting untuk kinerja human wayfinding, yaitu kemampuan manusia untuk menemukan jalan menuju suatu tempat.

Bertolak dari permasalahan tersebut, kami melakukan penelitian dengan mengambil studi kasus pada 5 bangunan pusat perbelanjaan di Depok, Jawa Barat. Ruang lingkup penelitian dibatasi pada hal-hal yang berkaitan dengan arsitektur, yaitu pemetaan terhadap elemen-elemen fisik. Untuk elemenelemen nonfisik, misalnya perilaku, hanya dibahas sebagai pemerkuat kajian terhadap elemen fisik yang dituju. Metoda yang digunakan adalah memetakan tempat kegiatan dan memetakan penanda, untuk memahami bagaimana bangunan merespon pengunjung dalam berorientasi dan bergerak mencapai tempat-tempat yang dituju dengan mudah.

Temuan dari penelitian ini adalah elemen wayfinding terdiri atas elemen spasial dan penanda, yang masing-masing harus memenuhi kriteria visibilitas (kemudahan untuk dilihat), legibilitas (kemudahan untuk dimengerti), dan imajibilitas (kemudahan untuk diingat) agar dapat melakukan kinerjanya dengan baik. Elemen tersebut adalah konfigurasi ruang, jalur sirkulasi, entrancelexit, landmark, sign/signage, vista navigasi, dan information desk.

Kata Kunci : visibilitas, legibilitas, imajibilitas

\footnotetext{
${ }^{1}$ Staf Pengajar pada Jurusan Arsitektur Universitas Jayabaya Jakarta, email adityafzn125@ gmail.com
} 


\section{A. Pendahuluan}

Pengertian wayfinding secara umum adalah kemampuan untuk mengetahui di mana seseorang berada, kemana tujuannya, dan cara terbaik untuk mencapainya, mengenali kapan telah mencapai tujuan tersebut, dan mencari jalan keluar, yang kesemuanya dilakukan di tempat yang aman dan secara independen. (The National Institute on Disability and Rehabilitation Research , NIDRR (2001))

Tolok ukur suatu sistem wayfinding yang berhasil harus menyediakan informasi bagi pemakai untuk:

- mengkonfirmasi mereka berada di awal yang benar atau menyelesaikan satu titik perjalanan

- mengidentifikasi lokasi mereka di dalam bangunan atau ruang eksternal, meyakinkan mereka menuju ke arah yang benar

- menyesuaikan diri di dalam bangunan atau ruang eksternal, memahami lokasi dan potensi setiap bahaya, mengidentifikasi tujuan mereka pada saat kedatangan, dan mampu menyelamatkan diri dengan aman dalam keadaan darurat.

\section{B. Kajian Pustaka}

Beberapa studi yang sudah dilakukan antara lain, 1) Jerry Weisman (Pennsylvania State University, 1981) pada studinya mengenai hubungan lingkungan dan manusia telah melihat faktor-faktor yang mempengaruhi wayfinding di gedung-gedung dan menemukan bahwa konfigurasi denah ruang adalah paling berpengaruh, diikuti oleh landmark spasial, diferensiasi spasial, signage dan nomor ruang; 2) Aysu Baskaya dkk. (Gazi University, Ankara, 2004) dalam penelitiannya yang berjudul Wayfinding in an Unfamiliar Environment: Different Spatial Settings of Two Polyclinics, mengeksplorasi orientasi spasial dan perilaku wayfinding pendatang baru di lingkungan yang asing dan untuk menekankan pentingnya landmark dan diferensiasi spasial dalam akuisisi lingkungan; 3) Elif Helvacıoğlu dan Nilgün Olguntürk (Bilkent University, Ankara, Turkey, 2010) dalam penelitiannya mengenai “Colour and Wayfinding”, menemukan bahwa kesulitan navigasi pada bangunan menunjukkan kebutuhan untuk mendukung navigasi dengan elemen desain, yaitu elemen desain informasi yang berupa sesuatu dari signage dengan menampilkan informasi digital dan elemen desain arsitektur yang berupa visibilitas pada tata letak bangunan dan landmark dalam bangunan; 4) Gunawan Tanujaya dkk (Universitas Petra, 2011), pada penelitiannya yang berjudul Evaluasi Sistem Wayfinding dan Orientasi di Gedung Universitas Kristen Petra, menemukan Architectural Element Wayfinding yang mudah untuk dimengerti (legible) dan diingat (imageable). 


\section{Metoda Penelitian}

Metode penelitian yang akan digunakan adalah:

a. Tahap Pengumpulan Data

1. Place Mapping (Pemetaan Tempat), adalah memetakan secara arsitektural ruang di dalam bangunan tempat pengunjung melakukan kegiatan, meliputi pola tata ruang / denah dan pola sirkulasi.

2. Signage Mapping (Pemetaan Penanda), adalah memetakan elemen-elemen yang digunakan sebagai petunjuk arah atau tempat yang akan dituju oleh pengunjung.

b. Tahap Interpretasi Data

1. Mengorganisasi informasi.

2. Membaca dan menginterpretasikan keseluruhan informasi.

3. Membuat suatu uraian terperinci mengenai kasus dan konteksnya.

c. Tahap Analisis

Menganalisis temuan-temuan yang didapat di lapangan, mencari kaitan sebab akibat satu dengan lainnya, sehingga dapat menemukan jawaban dari pertanyaan penelitian.

\section{Pembahasan}

Pemetaan pada kelima kasus mengacu pada kesimpulan dari kajian pustaka sebelumnya, yaitu bahwa Wayfinding terkait pada dua hal, yaitu elemen spasial dan elemen penanda.

A. Elemen Spasial meliputi :

- Konfigurasi Ruang

- Jalur Sirkulasi

- Entrance/Exit

- Landmark

B. Elemen Penanda meliputi :

- Sign

- Vista navigasi

- Information Desk

Dari kelima kasus yaitu: K1) Margocity, K2) Depok Town Square, K3) Depok Mall, 4) ITC Depok, dan 5) Plaza Depok, pemetaan dilakukan meliputi elemen-elemen tersebut di atas. Terlihat adanya keragaman pada konfigurasi ruang dan jalur sirkulasi yang merupakan elemen utama spasial. 
Semakin sederhana pola ruang, pengunjung lebih mudah melakukan orientasi dan mobilisasi, contoh pada K1 dan K3. Sedangkan penggunaan pola grid memberikan banyak pilihan jalur sirkulasi, tanpa penanda yang jelas pengunjung mengalami kesulitan orientasi tempat. Sedangkan emelen penanda lebih bersifat sebagai "alat bantu" bagi pengunjung untuk menemukan jalan dan tujuannya. Keragaman elemen penanda terlihat pada kelima kasus ini.

Berikut adalah Tabel Pemetaan Spasial dan Penanda pada kelima kasus: 


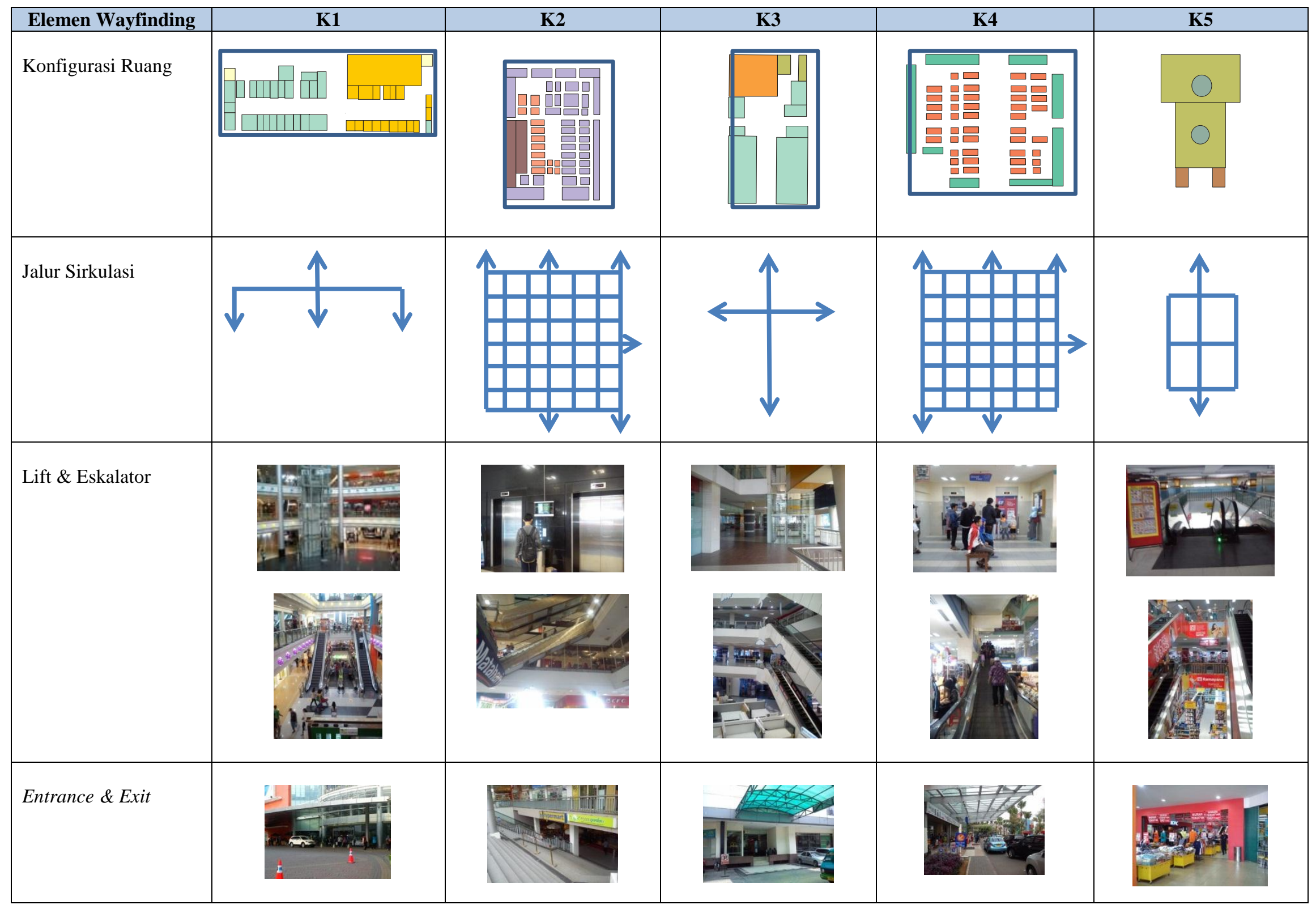




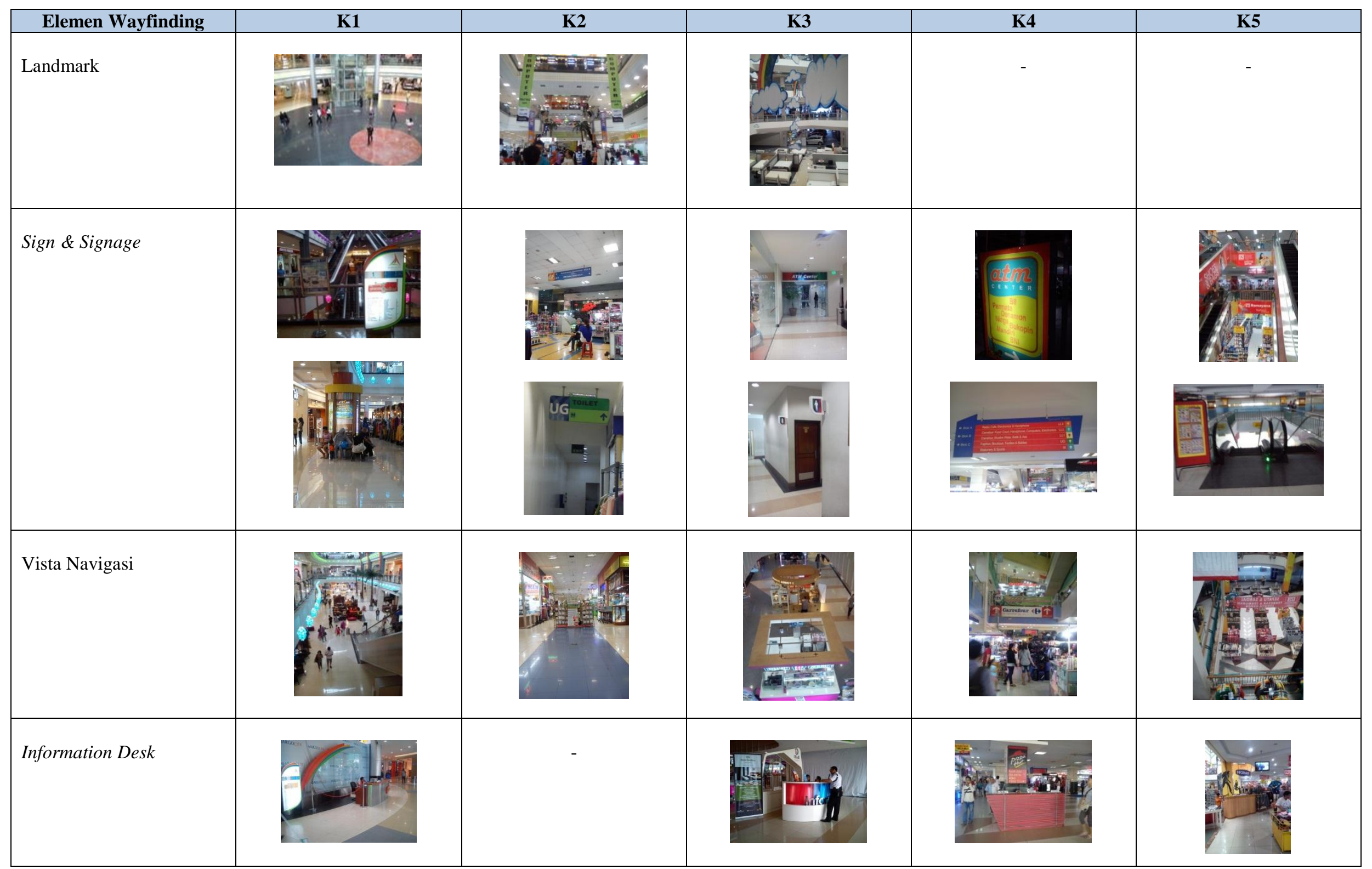


Konsep yang tepat untuk perancangan bangunan publik dengan pendekatan kemudahan wayfinding adalah merencanakan elemen spasial dan penanda yang memenuhi kriteria performansi sebagai berikut:

- Visibilitas, yaitu kemudahan untuk dilihat

- Legibilitas, yaitu kemudahan untuk dimengerti

- Imajibilitas, yaitu kemudahan untuk diingat.

\begin{tabular}{|c|c|c|c|}
\hline \multirow{2}{*}{ Elemen Wayfinding } & \multicolumn{3}{|c|}{ Kriteria Performansi } \\
\hline & Visibilitas & Legibilitas & Imajibilitas \\
\hline Jalur Sirkulasi & $\begin{array}{l}\text { - Dihindari jalur sirkulasi yang tertutup, atau } \\
\text { buntu di ujung jalur; }\end{array}$ & $\begin{array}{l}\text { - Sistem koridor sederhana, tidak banyak } \\
\text { persimpangan; }\end{array}$ & $\begin{array}{l}\text { - Hirarki jalur terstruktur dari utama ke } \\
\text { sekunder/cabang; }\end{array}$ \\
\hline Landmark & $\begin{array}{l}\text { - Lokasi penempatan strategis, bisa dilihat dari } \\
\text { berbagai arah; }\end{array}$ & $\begin{array}{l}\text { - Mempunyai titik tarik visual, antara lain } \\
\text { bentuk, warna, tekstur, tanda-tanda dan } \\
\text { ukuran. }\end{array}$ & $\begin{array}{l}\text { - Dapat berupa kekhasan arsitektur, elemen } \\
\text { struktur, atau bagian dari ruang; }\end{array}$ \\
\hline Sign/Signage & $\begin{array}{l}\text { - Lokasi penempatan strategis, bisa dilihat dari } \\
\text { berbagai arah, sesuai dengan kebutuhan dan } \\
\text { kepentingan navigasi pemakai; }\end{array}$ & $\begin{array}{l}\text { - Tulisan atau simbol yang dipakai mudah } \\
\text { dibaca dan dimengerti; }\end{array}$ & $\begin{array}{l}\text { - Mempunyai titik tarik visual, antara lain } \\
\text { bentuk, warna, tekstur, dan ukuran; }\end{array}$ \\
\hline Information Desk & $\begin{array}{l}\text { - Lokasi penempatan strategis, bisa dilihat dari } \\
\text { berbagai arah. }\end{array}$ & $\begin{array}{l}\text { - Mempunyai titik tarik visual, antara lain } \\
\text { bentuk, warna, tekstur, tanda-tanda dan } \\
\text { ukuran. }\end{array}$ & $\begin{array}{l}\text { - Sebagai bagian dari desain interior, } \\
\text { menciptakan bentuk yang unik dan } \\
\text { fungsional. }\end{array}$ \\
\hline
\end{tabular}




\section{E. DAFTAR PUSTAKA}

- Baskaya,Aysu dkk. (2004), Wayfinding in an Unfamiliar Environment: Different Spatial Settings of Two Polyclinics, Gazi University, Ankara.

- Bungin, B. (2007), Penelitian Kualitatif, Prenada Media Group, Jakarta.

- Carattin (2011), Wayfinding Architectural Criteria for the Design of Complex Environments in Emergency Scenarios, in Evacuation Andhuman Behavior in Emergency Situations, Universitad de Cantabria.

- Creswell, J. W. (1998), Qualitatif Inquiry and Research Design, Sage Publications, Inc.

- Dirjen DIKTI Kemendikbud (2012), Panduan Pelaksanaan Penelitian di Perguruan Tinggi, Edisi VIII.

- Natalisa, Adityarini, dan Hidayat, Hurip (2013), Wayfinding pada Bangunan Pusat Perbelanjaan di Depok Jawa Barat, Penelitian Hibah Pemula DIKTI, Universitas Jayabaya.

- Tanujaya, Gunawan dkk, (2011), Evaluasi Sistem Wayfinding dan Orientasi di Gedung Universitas Kristen Petra, Universitas Petra.

- The National Institute on Disability and Rehabilitation Research, NIDRR (2001).

- Weisman, Jerry (1981), Evaluating Architectural Legibility: Wayfinding and The Built Environment, Environment and Behavior, the Pennsylvania State University.

- Helvacioğlu \& Olguntürk (2010), Colour and Wayfinding, Department of Interior Architecture and Environmental Design, Bilkent University, 06800 Ankara, Turkey. 